\title{
Avaliação de provas de fase aguda em crianças e adolescentes com artrite idiopática juvenil e sua correlação com atividade da doença
}

\author{
Acute phase reactants evaluation in children and adolescents with juvenile idiopathic arthritis \\ and its correlation with disease activity
}

Aline Alencar M. F. Nicácio ${ }^{1}$, Karine Cobucci Damazio², Maria Teresa de S. L. R. A. Terreri³, Ivan Elias Rassi', Maria Odete E. Hilário ${ }^{5}$

\section{RESUMO}

Objetivo: Analisar a relação entre as provas de fase aguda e a atividade clínica da artrite idiopática juvenil e avaliar a concordância entre velocidade de hemossedimentação e proteína $C$ reativa (VHS e PCR) na fase aguda da doença.

Métodos: Foi realizado estudo retrospectivo tipo coorte a partir da análise de prontuários de 30 crianças e adolescentes que preenchiam os critérios diagnósticos para artrite idiopática juvenil, estavam em atendimento em ambulatório de Reumatologia Pediátrica e haviam realizado as provas de fase aguda (VHS e PCR).

Resultados: Dos 30 pacientes, 21 (70\%) eram do sexo feminino e $19(63,3 \%)$ apresentavam o subtipo oligoarticular da doença. A média de idade de início dos sintomas foi 65,6 meses, a idade de diagnóstico de 85,3 e o tempo de evolução, 57,2 meses. As provas de fase aguda mostraram associação positiva com a atividade de doença. A anemia não teve relação com a atividade de doença. A concordância entre as duas provas de fase aguda foi superior a $80 \%$.

Conclusões: As provas de fase aguda mantêm relação positiva com a atividade da doença e o seu uso concomitante aumenta a especificidade.

Palavras-chave: artrite idiopática juvenil; proteínas da fase aguda; reagentes da fase aguda; proteína C-reativa.

Instituição: Disciplina de Alergiologia, Imunologia Clínica e Reumatologia do Departamento de Pediatria da Universidade Federal de São Paulo (Unifesp), São Paulo, SP, Brasil

${ }^{1}$ Aluna de especialização do setor de Reumatologia Pediátrica da Disciplina de Alergologia, Imunologia Clínica e Reumatologia do Departamento de Pediatria da Unifesp, São Paulo, SP, Brasil

${ }^{2}$ Residente de Pediatria do Hospital Professor Edmundo Vasconcelos, São Paulo, SP, Brasil

${ }^{3}$ Professora afiliada do setor de Reumatologia Pediátrica da Disciplina de Alergologia, Imunologia Clínica e Reumatologia do Departamento de Pediatria da Unifesp, São Paulo, SP, Brasil

${ }^{4}$ Chefe do Laboratório de análises clínicas do Hospital Professor Edmundo Vasconcelos, São Paulo, SP, Brasil

${ }^{5}$ Professora-associada; chefe do setor de Reumatologia Pediátrica da Disciplina de Alergologia, Imunologia Clínica e Reumatologia do Departamento de Pediatria da Unifesp, São Paulo, SP, Brasil

\section{ABSTRACT}

Objective: To analyze the relationship between the acute phase reactants and the disease activity of Juvenile Idiopathic Arthritis (JIA) and to evaluate the agreement between erythrocyte sedimentation rate and $\mathrm{C}$-reactive protein during the acute phase of the disease.

Methods: a cohort retrospective study has been conducted based on the analysis of 30 children and adolescents who fulfilled the diagnostic criteria of JIA. All of them were in current follow-up at the pediatric rheumatology outpatient clinic and had acute phase reactants blood tests performed.

Results: Studied population comprised 30 patients: 21 (70\%) of them were females and $19(63.3 \%)$ presented oligoarticular subtype. The mean age at disease onset was 65.6 months; the age at diagnosis was 85.3 months and the followup had 57.2 months of duration. The acute phase reactants showed positive association with the disease activity. Anemia was not associated with disease activity. During the acute phase of the disease, agreement between erythrocyte sedimentation rate and C-reactive protein was greater than $80 \%$.

Conclusions: The acute phase reactants have a positive association with the activity of the disease and using both tests simultaneously increases their specificity.

Key-words: juvenile idiopathic arthritis; acute-phase proteins; acute-phase reactants; $\mathrm{C}$-reactive protein.

Endereço para correspondência:

Maria Teresa de S. L. R. A. Terreri

Rua Loefgreen, 2.38, apto. 141 - Vila Mariana

CEP 04040-004 - São Paulo/SP

Email: teterreri@terra.com.br

Recebido em: 15/7/08

Aceito em: 4/12/08 


\section{Introdução}

O termo Artrite Idiopática Juvenil (AIJ) compreende um grupo heterogêneo de doenças caracterizado por artrite em pelo menos uma articulação, com um mínimo de seis semanas de duração e sintomas com início até os 16 anos de idade ${ }^{(1)}$. Sua evolução pode ser mono ou policíclica, com períodos de atividade e de remissão, e com atividade persistente algumas vezes. Os critérios de remissão de AIJ foram definidos em um consenso e incluem: ausência de artrite ativa; ausência de febre, rash, serosite, esplenomegalia ou adenomegalia generalizada atribuída à AIJ; ausência de uveíte ativa, psoríase ou entesite; velocidade de hemossedimentação (VHS) ou proteína C-reativa (PCR) normais (se ambas forem testadas, devem estar normais); avaliação global pelo médico indicando o melhor escore possível para doença inativa ${ }^{(2,3)}$.

O diagnóstico é basicamente clínico, já que sua avaliação laboratorial é inespecífica. Testes laboratoriais são usados para excluir outras patologias, identificar os subtipos de doença associada a marcadores sorológicos e imunológicos específicos e para avaliar o grau de inflamação e seus efeitos sistêmicos. Os marcadores inflamatórios, como VHS e PCR, podem estar relacionados à presença, à extensão e à gravidade de processos inflamatórios ou infecciosos. Contudo, a análise isolada de qualquer um desses parâmetros não é suficiente para indicar a exacerbação da doença ${ }^{(2,4,5)}$. Em estudo realizado por Ramos et al, observou-se que anemia e elevações de VHS e PCR se associavam significativamente com a atividade articular em pacientes com AIJ dos subtipos poliarticular e oligoarticular ${ }^{(6)}$.

Devido ao fato de não estar bem estabelecido o verdadeiro valor das provas de fase aguda na atividade e na remissão da AIJ, sobretudo da VHS e da PCR, projetou-se o presente estudo, que objetivou analisar a relação entre as provas de fase aguda e a atividade clínica da artrite idiopática juvenil, além de avaliar a concordância entre velocidade de hemossedimentação e proteína C-reativa (VHS e PCR) na fase aguda da doença em pacientes em acompanhamento ambulatorial no Setor de Reumatologia do Departamento de Pediatria da Universidade Federal de São Paulo (Unifesp).

\section{Métodos}

Trata-se de um estudo retrospectivo tipo coorte. Avaliaram-se 30 crianças e adolescentes atendidos em ambulatório de Reumatologia Pediátrica durante o ano de 2007 e que preenchiam os critérios diagnósticos para $\mathrm{AIJ}^{(1)}$. Os critérios de exclusão foram: infecções virais, bacterianas ou fúngicas e síndrome de ativação macrofágica (SAM). Os responsáveis pelos pacientes assinaram consentimento livre esclarecido, e o estudo foi aprovado pelo Comitê de Ética em Pesquisa da Unifesp.

Os dados dos pacientes foram coletados nas consultas realizadas durante o acompanhamento no serviço, por meio de revisão de informações dos prontuários médicos. Alguns pacientes submeteram-se a mais de uma avaliação; nesses casos, foram consideradas as avaliações com intervalo de aproximadamente seis meses.

As variáveis analisadas foram: sexo, idade de início dos sintomas, idade do diagnóstico, tempo de evolução, subtipo de doença, número de articulações com artrite (presença de derrame articular ou dois dos seguintes sinais: calor, dor, hiperemia e perda de função) ou com limitação, tratamento utilizado (anti-inflamatórios não hormonais, corticosteroides, drogas modificadoras de doença, cloroquina, agentes antifator de necrose tumoral e gamaglobulina), provas de fase aguda (VHS, PCR) e nível de hemoglobina (Hb). Foi considerada atividade clínica a presença de artrite e/ou uveíte e/ou sinais ou sintomas sistêmicos.

Vinte e seis pacientes estavam fazendo uso de antiinflamatório não hormonal (19 oligoarticulares, seis poliarticulares e um sistêmico); seis estavam em tratamento com corticosteroide (dois oligoarticulares, três poliarticulares e um sistêmico); 22 com droga modificadora de doença (13 oligoarticulares, seis poliarticulares e três sistêmicos); dez com cloroquina (oito oligoarticulares, um poliarticular e um sistêmico); dois com antifator de necrose tumoral (um oligoarticular e um sistêmico) e um paciente com gamaglobulina (sistêmico).

Os seguintes valores foram considerados alterados: VHS $>20 \mathrm{~mm} / 1^{a}$ hora (método Winthrobe), PCR positiva (método Turbidimetria) e $\mathrm{Hb}<12 \mathrm{~g} / \mathrm{dL}$. A presença de associação entre AIJ, com ou sem atividade, com a alteração de VHS e/ou PCR foi estudada por meio do teste de qui-quadrado ou do teste exato de Fisher. Considerou-se significante $p<0,05$.

\section{Resultados}

Dos 30 pacientes avaliados, $21(70 \%)$ eram do sexo feminino, com média de idade de início dos sintomas de 65,6 meses (13 a 192), idade de diagnóstico de 85,3 meses (15 a 204) e tempo de evolução de 57,2 meses (2 a 168). Os subtipos de AIJ encontrados foram: $19(63,3 \%)$ oligoarticular, nove (30\%) poliarticular e dois casos $(6,7 \%)$ do subtipo sistêmico. 
Os 30 pacientes foram submetidos a 99 avaliações clínicas. Dessas avaliações, 69 (69,7\%) mostravam doença ativa e 30 $(30,3 \%)$, inativa.

A VHS > 20mm ocorreu em $39 \%$ dos pacientes com AIJ, em $53 \%$ no subtipo poliarticular e em $29 \%$ dos pacientes portadores do subtipo oligoarticular. Já a PCR positiva foi observada em 36, 45 e 29\%, respectivamente. A anemia esteve presente em $25 \%$ de todas as formas clínicas, em $38 \%$ no subtipo poliarticular e em $17 \%$ no subtipo oligoarticular.

A Tabela 1 mostra a relação da elevação da VHS e da PCR e da diminuição de $\mathrm{Hb}$ com a atividade de doença nos subtipos poliarticular, oligoarticular e sistêmico. Houve associação significante entre a atividade de doença e a elevação de VHS, assim como de PCR nos subtipos poliarticular e oligoarticular. Devido ao pequeno número de pacientes com a forma sistêmica de apresentação da AIJ, a análise estatística entre as alterações laboratoriais e a atividade da doença ficou prejudicada nesse subtipo.

A Tabela 2 mostra a relação entre a elevação de VHS e a atividade da doença em todos os subtipos clínicos. A especificidade do exame para a atividade da doença foi de $93 \%$ e o valor preditivo positivo foi $94 \%$.

A Tabela 3 mostra a relação entre a elevação da PCR e a atividade da doença em todos os subtipos clínicos. A especificidade do exame para a atividade da doença e o valor preditivo positivo foram, respectivamente, 93 e 94\%. A análise da redução de $\mathrm{Hb}$ de acordo com a atividade da doença mostrou que o valor preditivo positivo e a especificidade da anemia como marcadores de atividade da doença foram menores (84 e $86 \%$, respectivamente).

Tabela 1 - Frequência de alteração de velocidade de hemossedimentação, proteína C-reativa e hemoglobina, de acordo com a atividade da doença nos subtipos poliarticular, oligoarticular e sistêmico

\begin{tabular}{lcccc}
\hline & $\begin{array}{c}\text { Número de } \\
\text { avaliações (n) }\end{array}$ & Atividade presente & Atividade ausente & $\boldsymbol{p}$ \\
\hline VHS >20mm & $17 / 32$ & $16 / 24$ & $1 / 8$ & 0,008 \\
Poliarticular & $17 / 59$ & $16 / 40$ & $1 / 19$ & $<0,001$ \\
Oligoarticular & $5 / 8$ & $5 / 5$ & $0 / 3$ & - \\
Sistêmico & & & & 0,003 \\
PCR positiva & $14 / 31$ & $14 / 23$ & $0 / 8$ & 0,032 \\
Poliarticular & $16 / 56$ & $14 / 37$ & $2 / 19$ & - \\
Oligoarticular & $4 / 8$ & $4 / 5$ & $0 / 3$ & 0,676 \\
Sistêmico & $12 / 32$ & $10 / 24$ & $2 / 8$ & 0,365 \\
Hb <12g/dL & $10 / 59$ & $8 / 40$ & $2 / 19$ & - \\
Poliarticular & $3 / 8$ & $3 / 5$ & $0 / 3$ & \\
Oligoarticular & & & & \\
Sistêmico & & & & \\
\hline
\end{tabular}

VHS: velocidade de hemossedimentação; PCR: proteína C-reativa; HB: hemoglobina

Tabela 2 - Frequência de alteração de velocidade de hemossedimentação de acordo com a atividade de doença em todos os subtipos

\begin{tabular}{lccc}
\hline & Atividade presente & Atividade ausente & Total \\
\hline VHS positivo $(>20 \mathrm{~mm})$ & 37 & 2 & 39 \\
VHS negativo $(<20 \mathrm{~mm})$ & 32 & 28 & 60 \\
Total & $\mathbf{6 9}$ & $\mathbf{3 0}$ & $\mathbf{9 9}$ \\
\hline
\end{tabular}

Sensibilidade: 53\%; especificidade: $93 \%$; valor preditivo positivo: $94 \%$; valor preditivo negativo: $46 \%$

Tabela 3 - Frequência de alteração de proteína C-reativa de acordo com a atividade de doença em todos os subtipos

\begin{tabular}{lccc}
\hline & Atividade presente & Atividade ausente & Total \\
\hline PCR positiva & 32 & 2 & 34 \\
PCR negativa & 33 & 28 & 61 \\
Total & $\mathbf{6 5}$ & $\mathbf{3 0}$ & $\mathbf{9 5}$ \\
\hline
\end{tabular}

Sensibilidade: 49\%; especificidade: $93 \%$; valor preditivo positivo: $94 \%$; valor preditivo negativo: $45 \%$ 
A Tabela 4 mostra a frequência de alteração de VHS e PCR de acordo com a atividade de doença em todos os subtipos. Essa análise mostrou que, quando ambas as provas de fase aguda estavam alteradas, todos os pacientes apresentavam doença ativa. As duas provas de fase aguda foram concomitantemente alteradas ou normais em 79 de 95 pacientes, o que mostra uma concordância de $83 \%$.

\section{Discussão}

No presente estudo, o sexo feminino foi o mais acometido, confirmando dados da literatura que mostram um predomínio da AIJ de duas a três vezes em mulheres ${ }^{(7)}$. Da mesma forma, a maior frequência do subtipo oligoarticular é mais observada na literatura, sendo relatada frequiência de 50 a $75 \%$ para o subtipo oligoarticular ${ }^{(6)}$.

O intervalo de até mais de um ano entre o início dos sintomas e o diagnóstico mostra que tanto o pediatra como o clínico têm dificuldade para o diagnóstico. Esse intervalo é um importante fator na determinação do prognóstico dos pacientes e, quanto menor for, maior será a probabilidade de boa evolução da $\mathrm{AIJ}^{(6)}$.

Embora o diagnóstico de AIJ seja clínico, os exames subsidiários, em especial as provas de fase aguda, são importantes para indicar a atividade de doença. Elas avaliam de forma inespecífica a presença e a gravidade do processo inflamatório. Além disso, alguns autores estabeleceram uma correlação frequente entre a VHS e a PCR. Ambas têm valor como critério de atividade e de remissão na $\mathrm{AIJ}^{(3,5)}$.

A VHS é um exame simples e de baixo custo que mede indiretamente a concentração do fibrinogênio e, em menor extensão, de outras proteínas de fase aguda. Altas concentrações dessas proteínas induzem hemácias suspensas no plasma à agregação, determinando queda mais rápida e maior velocidade de sedimentação. É um exame inespecífico, pois se eleva em infecções, neoplasias, traumas e doenças reumáticas, sofrendo influência do sexo, idade, alimentação, período do dia, uso de drogas, alterações no número, tamanho e forma das hemácias, anemia, gravidez e insuficiência cardíaca ${ }^{(4,5,8)}$.
O papel exato da PCR não está claro, mas sabe-se que tem correlação com a extensão de processos inflamatórios e infecciosos e sua gravidade. A PCR pode também inibir o crescimento de células tumorais, modular a função de polimorfonucleares e monócitos, agregar plaquetas e inibir a formação de linfócitos T dependentes. Ela aumenta dentro de minutos a horas após a agressão tecidual e reduz abruptamente depois que o estímulo inflamatório cessa. $\mathrm{O}$ único determinante dos valores séricos de PCR é a sua velocidade de síntese, podendo sofrer a influência do uso de medicamentos anti-inflamatórios ${ }^{(4,5,8)}$.

Como as infecções podem aumentar as provas de fase aguda e, com isso, levar a dificuldades de interpretação, a sua presença foi fator de exclusão no presente estudo. Além disso, vale ressaltar que pacientes com síndrome de ativação macrofágica foram excluídos do estudo. Trata-se de uma complicação da AIJ, uma doença rara, grave e com índice de mortalidade entre 8 e $22 \%{ }^{(8)}$. Tal complicação pode mimetizar septicemia ou reativação da doença de base, resultando em febre, hepatoesplenomegalia, adenomegalia, insuficiência hepática, quadro neurológico, exantema maculopapular, sangramentos de mucosa, pancitopenia, aumento das enzimas hepáticas, ferritina sérica maior que $10.000 \mathrm{ng} / \mathrm{mL}$, hipertrigliceridemia, hiponatremia e VHS baixa ${ }^{(8,9)}$.

No presente estudo, as alterações nas provas de fase aguda e no nível de hemoglobina foram mais encontradas no subtipo poliarticular do que no oligoarticular. Esse achado é similar ao relatado na literatura, que mostra o subtipo poliarticular como aquele de maior atividade inflamatória sistêmica, enquanto no oligoarticular a atividade é geralmente restrita ao local da artrite $\mathrm{(T)}^{(7)}$.

A alteração de VHS neste estudo mostrou-se estatisticamente associada à atividade da doença na AIJ em geral e aos subtipos poliarticular e oligoarticular especificamente. A alteração de PCR também esteve presente nas avaliações em que os pacientes se encontravam com doença ativa em todos os subtipos. Esses dados são semelhantes aos encontrados na literatura $^{(1,6)}$.

O presente estudo mostrou que a concomitância de alterações de VHS e de PCR teve alta especificidade para doença

Tabela 4 - Frequência de velocidade de hemossedimentação e proteína C-reativa alteradas na atividade da doença em todos os subtipos

\begin{tabular}{lccc}
\hline & Atividade presente & Atividade ausente & Total \\
\hline PCR e VHS positivas & 27 & 0 & 27 \\
PCR ou VHS positiva ou ambos negativas & 38 & 30 & 68 \\
Total & 65 & 30 & 95 \\
\hline
\end{tabular}

Sensibilidade: 42\%; especificidade: $100 \%$; valor preditivo positivo: $100 \%$; valor preditivo negativo: $44 \%$ 
ativa (100\%), isto é, todos os casos de doença inativa não apresentaram alteração concomitante de VHS e de PCR. Contudo, a alteração de apenas uma das referidas provas de fase aguda ou a normalidade dos valores de ambas pode ser encontrada tanto na doença ativa como na inativa. Além disso, a alteração de VHS teve valor preditivo positivo de $84 \%$, isto é, a maioria dos pacientes com atividade de doença apresenta VHS alterada. O mesmo foi observado para a PCR.

A literatura descreve a presença de anemia e atividade inflamatória da AIJ em todos os seus subtipos, principalmente no subtipo de início sistêmico ${ }^{(6)}$. Embora frequente, a anemia não manteve associação com a atividade da doença em nenhuma das formas clínicas de AIJ aqui analisadas.
Entretanto, devido ao pequeno número de pacientes com o subtipo sistêmico, não foi possível avaliar a associação das provas de fase aguda e nível de hemoglobina com a atividade de doença nesse subtipo.

A VHS e a PCR foram concordantes em $83 \%$, ou seja, em poucos casos uma das provas de fase aguda estava alterada e a outra normal ou vice-versa. Por isso, alguns autores acham desnecessária a realização dos dois testes laboratoriais. Entretanto, com base nos resultados deste estudo, pode-se concluir que, quando se realizam os dois exames, tanto a especificidade quanto o valor preditivo positivo em relação à atividade ou não de doença foi de $100 \%$, corroborando a importância da realização simultânea desses dois exames.

\section{Referências bibliográficas}

1. Petty RE, Southwood TR, Manners P, Baum J, Glass DN, Goldenberg J et al. International League of Associations for Rheumatology classification of juvenile idiopathic arthritis: second revision, Edmonton, 2001. J Rheumatol 2004;31:390-2.

2. Goldenstein-Schainberg C. Diagnóstico e tratamento da artrite crônica juvenil. In: Vieira ES, Hilário MO, editores. Diagnóstico e tratamento em reumatologia pediátrica e do adulto. Vitória: Ed do autor; 1998. p. 195-6.

3. Machado C, Ruperto N. Consenso em reumatologia pediátrica: Parte I - Definição dos critérios de doença inativa e remissão em artrite idiopática juvenil/ artrite reumatóide juvenil. Rev Bras Reumatol 2005;45:9-13.

4. Finger E, Scheinberg MA. Correlações clínico-laboratoriais dos exames em Reumatologia. In: Vieira ES, Hilário MOE, editores. Diagnóstico e tratamento em reumatologia pediátrica e do adulto. Vitória: Ed do autor; 1998. p. 350-1.
5. Serra CRB. Contribuição das provas de fase aguda na monitorização das doenças reumáticas. Rev Bras Reumatol 1997;37:152-8.

6. Ramos VC, Ronchezel MV, Okuda EM, Sacchetti SB. Caracterização epidemiológica, clínica e laboratorial de 100 crianças com artrite reumatóide de juvenil. Rev Paul Pediatr 2006;24:335-42.

7. Oliveira SKF. Artrite idiopática juvenil. In: Lopez FA, Campos Júnior D, editores Tratado de pediatria. São Paulo: Manole; 2007. p. 1911-31.

8. Ramos VC, Okuda EM. Síndrome de ativação macrofágica. In: Terreri MTRA Sacchetti SB. Reumatologia para o pediatra. São Paulo: Atheneu; 2008. p. 105-9

9. Petty RE, Cassidy JT. Systemic arthritis. In: Cassiy JT, Petty RE, Laxer RM, Lindsley CB, editors. Textbook of pediatric rheumatology. Philadelphia: Saunders; 2005. p. 295-6. 